\title{
Individual and contextual variables related to periodontal disease: multilevel analysis in underprivileged adolescents in Brazil
}

\begin{abstract}
The objectives of this study was to investigate the individual and contextual risk indicators of periodontal disease in underprivileged adolescents, and the disparity in distribution of the disease. Cross-sectional analytical study, conducted in the city of Piracicaba, SP, Brazil, in 2012. The probabilistic sample was composed of 1,130 adolescents from 15-19 years of age, randomly selected from 21 state schools and 34 Primary Health Units - Family Health (PHU-FH). The dependent variable studied was presence of periodontal disease (CPI). The independent variables were classified into individual (clinical, sociodemographic, psychosocial, self-perception, impact on oral health, access to services, pain reports and quality of life variables) and contextual (social exclusion index, total number of residents in suburb, literacy rate, percentage of home ownership residences, percentage of domestic sewerage, percentage of trash collected, percentage with income of over 1 minimum wage per month and percentage of families without monthly income). The multilevel regression model was estimated by the PROC GLIMMIX (Generalized Linear Models-Mixed) procedure, considering the individuals' variables as Level 2 and the contextual variables of the suburbs as Level 3. As regards the individual variables, the adolescents who never had toothache; with a lower impact on oral health; and resided in homes with higher percentage of domestic sewage presented less presence of periodontal disease. The individual and contextual variables were associated with the presence of periodontal disease in underprivileged adolescents, indicating that they must be taken into consideration in the formulation of policies directed towards oral health promotion and prevention activities in this group.
\end{abstract}

Keywords: periodontal disease, adolescents, dental, impacts, pain, social context
Volume 9 Issue 3 - 2018

Fabiana de Lima Vazquez,' Karine Laura Cortellazzi,' Jaqueline Vilela Bulgareli,' 'Valéria Silva Cândido Brizon,' Luciane Zanin, ${ }^{2}$ Luciane Miranda Guerra,' Elaine Pereira da Silva Tagliaferro, ${ }^{3}$ Glaucia Maria Bovi Ambrosano,' Fábio Luis Mialhe,' Antonio Carlos Pereira'

'Department of Community Dentistry, Piracicaba Dental School, State University of Campinas, Brazil

${ }^{2}$ Department of Public Health, Jundiaí Medical School, São Paulo, Brazil

${ }^{3}$ Department of Community Dentistry, Araraquara Denta School, State University of São Paulo, Brazil

\section{Correspondence: Valeria Silva Candido Brizon, Department} of Community Dentistry, Piracicaba Dental School, University of Campinas, Av. Limeira, 90 I-P.O. BOX 52, Zip code: I34|4-903, Piracicaba, São Paulo, Brazil, Tel 55-19-21065209, Fax 55-1921065200,Email valeriabrizon@gmail.com

Received: June 07,2017 | Published: June 20, 2018

\section{Introduction}

Periodontal disease is a destructive disease of the gingiva and supporting structures of the teeth, which develops through inflammatory processes induced by microbial biofilm. ${ }^{1}$ It is considered one of the main diseases affecting oral health, and is ranked as the second main Public Health problem in Dentistry. ${ }^{2}$ The World Health Organization recently informed that severe periodontitis affects $5-20 \%$ of the adult population, and the majority of children and adolescents present signs of gingivitis, ${ }^{3}$ which may attain a prevalence of up to $80 \%$ in adolescents. ${ }^{4,5}$ According to the last national oral health survey conducted in Brazil, over half the adolescents from 15 to 19 years of age present signs of the disease, such as bleeding $(9.7 \%)$, calculus $(28.6 \%)$ and periodontal pockets $(10.8 \%) .^{2}$ To reduce the inequalities in health has become a great priority of international public health, while the types of intervention in health will be potential challenges in the development of simulation models to investigate the health of the population. ${ }^{6}$ A few studies have demonstrated the impact of social determinants on oral health in adolescents, ${ }^{7-9}$ especially in the deprived group. Periodontal conditions have been based on the individual level. ${ }^{10-12}$ However, current studies have demonstrated the importance of the inclusion of contextual variables in the evaluation of oral health conditions in populations. ${ }^{13-16}$ Therefore, the use of multilevel analysis to model individual and contextual variables simultaneously, have provided broader perspectives about the inter-relationships between the two different levels of effects, and insights into how these relationships affect periodontal disease. This technique provides better estimates of the substantive meanings for group data in comparison with the traditional regression analysis. ${ }^{17,18}$ Adolescence is a stage of transition with psychic, physical, biologic and social changes. This period has its own characteristics according to the sociocultural environment in which the individual lives, and constitutes a group under constant exposure to various situations of physical, emotional and social risks. In view of the foregoing, it has become important to view the approach to youngsters from a psychosocial aspect ${ }^{19}$, demanding that health professionals analyze the problems that may arise from damage and health problems ${ }^{20-22}$. In adolescence, some habits are consolidated and others are molded, and have a strong influence on the lifestyle adopted for the adult stage. The habits acquired in childhood, such as infrequent tooth brushing, may represent a risk factor for the development of diseases in this age group. ${ }^{23}$ The concept of risk, initially associated with the biomedical model and with the concept of mortality, ${ }^{24,25}$ has gradually ceded space to the study of human development and its changes, ${ }^{26}$ adding a series of risk factors, including the individual, social, behavioral and psychosocial determinants ${ }^{24,27,28}$. When a child is exposed to risk 
factors within the family or community, it becomes vulnerable and is more propense to develop deficient oral health ${ }^{29}$. These social and material disadvantages experienced in childhood continue to have adverse effects on the child's physical and mental health throughout life. ${ }^{30,31}$ Another important aspect of interest is the relationship between periodontal health, perception and impact on daily activities. In addition to the traditional clinical measures, other measures related to self-perception of the child's oral health and the impact that oral diseases cause on its daily life have been studied. ${ }^{11,30,32-37}$ Considering the relevance that the focus on psychological and social aspects will bring to a new view of the relationship between oral health and quality of life, it has become important to conduct studies that incorporate and demonstrate this new form of evaluation of oral health conditions. Thus, the use of socio-dental indicators may be a good alternative for planning and providing dental services..$^{33,38,39,40}$ In spite of an increase in the number of studies on the impact of oral health con the quality of life in adolescents, in general, these studies have been restricted to specific populations such as adults and schoolchildren, and there have been a lower number of studies with adolescents. ${ }^{8,9,41}$ In the face of this scenario, and with a view to better qualification of public health policies for this group in a stage of transition, the aim of this study was to identify the individual and contextual risk indicators for periodontal disease in underprivileged adolescents in the southeastern region of Brazil, and to study the disparity of distribution of the disease.

\section{Materials and methods}

\section{Ethical aspects}

This study was approved by the Research Ethics Committee of FOP-UNICAMP in accordance with the Resolution 196/96 of the National Health Council, Ministry of Health, Protocol No. 027/2011.

\section{Type of study}

Analytical, cross-sectional, observational study.

\section{Study location}

This study was developed in the Municipality of Piracicaba, SP, Brazil, in the period from January to December, 2012, with adolescents from 15 to 19 years old, who were under the care of Primary Health Care- Health Family teams (PHC-HF), which provide primary health care for all family members residing in a circumscribed area (about 4000 persons). ${ }^{42}$ They were enrolled in public schools (located in the territories covered by these PHC-HF units) and in the PHC-FC units. The greatest extent of social exclusion in the municipality occurs in these regions. The city has an estimated population of 368,843 inhabitants, a Human Development Index (HDI) of 0.84 and has had a fluoridated public water supply since 1971 (0.7 ppmF).

\section{Setting}

The city is composed of 68 suburbs distributed throughout 5 administrative regions (North, South, East, West and Center) and there are a total number of 12,539 adolescents in the age-range from 15 to 19 years. The Northern Region consists of 14 suburbs with 2460 adolescents; Southern Region, 14 suburbs and 2510 adolescents; Eastern Region, 16 suburbs and 2491 adolescents; Western Region, 13 suburbs and 3330 adolescents; Downtown Region, 11 suburbs and 1748 adolescents. ${ }^{43}$ According to data from the Municipal Secretary for Health, in 2012 there were a total number of 34 PHC-FH units, and among them there were 12 units with Primary Dental Care (PDC) teams. On an average, 320 adolescents between the ages of 15 and 19 years were enrolled in each one of the PHU-FH unit, totaling approximately 11,000 individuals. According to the Secretary for Education, the municipality had 43 high schools and a total number of 9,356 schoolchildren in this age-range enrolled. It is important to emphasize that the PHC units are distributed in the less favored socioeconomic regions of the municipality. All public high schools $(n=21)$ in the territorial areas covered by the PHC were enrolled. In the 34 PHC units, the Free and Informed Consent Forms to participate in the Study were handed to the Community Health Agents during home visits. These agents also previously made the appointments for the time and day for participants to appear at the units. At the schools, the Forms were handed to the teachers who distributed them to the selected schoolchildren, in order to obtain the parents' or guardians' authorization afterwards.

\section{Sample}

The sample size was calculated in the software program epi info7 considering the level of confidence of $95 \%$, test power of $80 \%$, non exposed/exposed rate $=1, \%$ response in the non exposed group of $31.5 \%$ and $\mathrm{OR}=1.4$, admitting a sampling error of $5 \%$, sample loss of $20 \%$, thereby obtaining a sample of 1428 individuals from 15 to 19 years of age. Of these 1,428 adolescents initially selected, 298 failed to appear on the day of the exam or did not wish to participate. Thus, 221 individuals were examined at the 34 FHUs and 909 at the 21 state high schools, totaling 1,130 adolescents examined.

\section{Inclusion and exclusion criteria}

The inclusion criteria were absence of: systemic diseases, difficulties with communication, or neuromotor problems, absence of severe hypoplasia and absence of orthodontic appliance. Individuals who did not agree to participate in the study and those absent in the day of the exam were excluded from the sample.

\section{Clinical examination}

The exams were performed at the PHC-HF and at the schools by two examiners (previously calibrated, assisted by two note-takers), using the standardized clinical record chart, under artificial light, and with previous tooth brushing performed under supervision by an Oral Health Technician (OHT). For each exam, a CPI periodontal probe and a plane dental mirror No. $5^{44}$ were used. Data were collected relative to the following clinical characteristics: periodontal disease by the Community Periodontal Index (CPI) and use and need for a prosthesis, in accordance with the codes and criteria of the World Health Organization. ${ }^{44}$

\section{Training and calibration}

A Gold Standard examiner conducted the process of calibrating the two examiners for the clinical conditions. The theoretical-practical activities of the training and calibration exercises consisted of a total of 7 periods - 1 theoretical lasting 4 hours, 4 clinical training sessions of 4 hours each (total of 16h) and 2 calibration exercises lasting 4 hours (total of $8 \mathrm{~h}$ ). The training stage consisted of a theoretical discussion, afterwards followed by a practical stage, in which the examiners evaluated 12 adolescents per period, with differentiated prevalence of periodontal disease. Discussions between the examiners and the Gold Standard examiners were held with the purpose of obtaining an estimate of the extension and diagnostic nature, up to which point the 
acceptable consistency remained above 0.91 , measured by KAPPA statistics for all the clinical conditions. ${ }^{45}$ The final calibration exercise consisted of 2 periods (total of $8 \mathrm{~h}$ ) with mean inter-examiner Kappa values of 0.95 . In order to verify maintenance of the diagnostic criteria and intra-examiner error, $10 \%$ of the sample were re-examined, with mean Kappa values of 0.96 .

\section{Study variables and instruments}

The individual and contextual variables analyzed are described in Table 1.

Table I Individual and contextual variables

\begin{tabular}{|c|c|c|}
\hline & Cl: & Periodontal Disease \\
\hline & 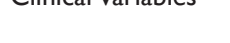 & Use and need for dental prosthesis \\
\hline & & Age \\
\hline & & Sex \\
\hline & & Monthly Family Income \\
\hline & & Number of persons in the family \\
\hline & & Fathers' and Mothers' Educational Level \\
\hline & Sociodemographic & Type of housing \\
\hline & variables of the & Family Grant Program family \\
\hline & $\begin{array}{l}\text { adolescent and } \\
\text { family }\end{array}$ & Prison inmate in the family \\
\hline & & Has lived in a city other than Piracicaba \\
\hline & & Number of siblings \\
\hline & & Failure to pass end of year school tests \\
\hline & & Adolescent works \\
\hline & & Father and mother work \\
\hline $\begin{array}{l}\text { Individual } \\
\text { variables }\end{array}$ & Self-perception & $\begin{array}{l}\text { How do you classify the health of your } \\
\text { teeth and mouth? }\end{array}$ \\
\hline & $\begin{array}{l}\text { and Impact on } \\
\text { Oral Health }\end{array}$ & $\begin{array}{l}\text { Are you satisfied with the appearance } \\
\text { of your teeth }\end{array}$ \\
\hline & & OIDP \\
\hline & & Have you ever been to the dentist? \\
\hline & & $\begin{array}{l}\text { What type of dental service do you } \\
\text { generally use? }\end{array}$ \\
\hline & & $\begin{array}{l}\text { When was the last time you went to } \\
\text { the dentist? }\end{array}$ \\
\hline & $\begin{array}{l}\text { Access to Services } \\
\text { And pain report }\end{array}$ & $\begin{array}{l}\text { Why did you go to the dentist the last } \\
\text { time? }\end{array}$ \\
\hline & & $\begin{array}{l}\text { What is your most frequent reason for } \\
\text { going to the dentist? }\end{array}$ \\
\hline & & Have you ever had toothache? \\
\hline & & $\begin{array}{l}\text { Have you had toothache in the last } 6 \\
\text { months }\end{array}$ \\
\hline & Quality of Life & WHOQOL-bref \\
\hline
\end{tabular}

$\begin{array}{lll} & \text { Social Exclusion Index } \\ & \text { Total number of residents per suburb } \\ & \text { Literacy Rate } \\ & \% \text { of home ownership } \\ & \% \text { domestic sewage facilities } \\ \text { variables } & \text { suburbs } & \text { \% garbage collected } \\ & & \% \text { with income up to } 0.5 \text { minimum } \\ & \text { wage } \\ & \% \text { with income up to I minimum wage } \\ & \% \text { with income over I minimum wage } \\ & \% \text { without monthly income }\end{array}$

\section{Individual variables}

A questionnaire was applied to collect the sociodemographic variables ${ }^{46}$ and another to obtain information on psychosocial, selfperception of health, access to health services and report of pain variables. ${ }^{47}$ The instruments used for evaluating quality of life and socio-dental impact were the WHOQOL-bref and OIDP (Oral Impacts on Daily Performances) respectively. The WHOQOL-bref refers to an index of a transcultural nature, which appreciates the individual perception of the person with regard to his/her quality of life. It consists of 26 questions, with 2 general questions being about the quality of life and the other 24 questions representing the four domains: physical; psychological; social relationships and environment. Each domain is composed of questions with responses ranging from 1 to 5 , so that the closer the score is to 5 , the better the quality of life. ${ }^{48}$ Developed by Adulyanon et al., ${ }^{32}$ the OIDP is a sociodental indicator, with focus on the measure of impact that interferes in people's ability to perform their daily activities. It measures the oral impacts that affect 8 daily performances, classified as physical (eating and appreciating food, speaking and clearly pronouncing words, cleaning the teeth), psychological (sleeping and relaxing, smiling, laughing and showing the teeth without embarrassment, maintaining a normal emotional state without becoming irritated) and social (working, playing a social role and finding satisfaction in social encounters). It uses a logical approach to quantify the impact, evaluating the frequency and severity distributed on a scale of 5 points. The score of the severity measures gives the relative importance of the informant's perception of the impact on daily performance. The Basic Care Information System (SIAB) is an instrument used by the Brazilian Primary Healthcare System to enroll the families in the territory covered by the PHC-HF units and records socio-sanitary data and those relative to the living conditions of these persons, with the aim of planning the interventions and health care. ${ }^{49}$ By means SIAB it was possible to obtain information with reference to the adolescent's family belonging to an income transfer program (Family Grant Program) ) $^{50}$ and whether there was any family member serving a prison sentence. Brazil instituted the Family Grant Program (FGP) in 2004, with the purpose of transferring income directly to families in a situation of poverty and extreme poverty, and guarantee the right to basic social services, making it possible to benefit 16 million Brazilians $(8.5 \%$ of the population). ${ }^{51}$ 


\section{Contextual variables}

The Social Exclusion Index (SEI) of the 36 suburb where the adolescents resided was collected at the Piracicaba Research and Planning Institute and the Municipal Secretary for Social Development. ${ }^{52}$ The purpose was the quantitative dimensioning of some of the attributes of social inequalities between the suburbs, ranging from -1 (suburbs with the worst indices - most vulnerable) to 1 (suburbs with the best indices - least vulnerable). Of the 1,130 study subjects, $1,087(96.1 \%)$ resided in suburbs with the worst social exclusion indices (negative indices). Other information with reference to suburbs where the adolescents resided (total number of residents per suburb, literacy rate, $\%$ of home ownership, $\%$ domestic sewage available, $\%$ garbage collected, $\%$ with income of up to 0.5 minimum wage, $\%$ with income from 0.5 to 1 minimum wage, $\%$ with income higher than 1 minimum wage and \% without monthly income) were obtained from the Brazilian Institute of Geography and Statistics. ${ }^{53}$

\section{Data analysis}

In the present study, the CPI was considered a response variable. The multilevel regression models were estimated by the PROC GLIMMIX procedures; that is "Generalized Linear Models-Mixed" of the SAS statistical program. ${ }^{54}$ In the analysis, the individual variables were considered Level 1 and those of the suburbs, Level 2; and adjustment of the model was evaluated by -2 Res Log Likelihood (the lower, the better fit the model). Initially, a model was estimated with the intercept only, in order to study the proportion of variance due to the suburbs in relation to the individuals. This model served as the basis for evaluating the reduction in the variance of the other models studied (Model 1). After this, the individual variables (Model 2) were tested, and later those of the suburbs were included (Model 3).

\section{Results}

In this study, the final sample was composed of 1,130 adolescents with a mean age of 15.3 years (standard deviation=1.05), thus attaining a response rate of $79.13 \%$. Of these, $632(55.93 \%)$ were female and $498(44.07 \%)$ were male. The majority of the adolescents related that they had experienced toothache at least once in their lives (74.17\%), $39.96 \%$ classified the health of their teeth and mouth as good, and $39.91 \%$ related impact of oral health on their day to day life. As regards monthly family income, the larger portion of the volunteers came from families with an income of between 2 and 5 minimum wages. The prevalence of periodontal disease was $58 \%$ Table 2 .

Table 2 Sample description

\begin{tabular}{lll}
\hline Variables & $\mathbf{n}$ & $\%$ \\
\hline Sex & & \\
Female & 632 & 55.93 \\
Male & 498 & 44.07 \\
Age (years) & & \\
15 & 776 & 68.67 \\
16 & 222 & 19.65 \\
17 & 81 & 7.17 \\
18 & 29 & 2.57 \\
19 & 22 & 1.95 \\
Number of persons in the family & & \\
Up to 2 & 28 & 2.5
\end{tabular}

$\begin{array}{ll}3 & 154 \\ 4 & 332 \\ 5 & 283 \\ 6 & 169 \\ \text { Over 6 } & 153\end{array}$

Have you ever had toothache during your life? $\mathrm{No}$

Don't know/Don't remember

Need for Dentures

Does not require

Need for a single-element dental prosthesis

Need for multiple-element dental prosthesis.

How would you classify the health of your teeth

\begin{tabular}{|c|c|c|}
\hline Excellent & 59 & 5.24 \\
\hline Very good & 216 & 19.18 \\
\hline Good & 450 & 39.96 \\
\hline More or Less & 356 & 31.62 \\
\hline Poor & 45 & 4 \\
\hline \multicolumn{3}{|c|}{ When was the last time you went to the dentist? } \\
\hline $\begin{array}{l}\text { I am undergoing treatment at } \\
\text { present }\end{array}$ & 233 & 22.11 \\
\hline Less than 6 months ago & 326 & 30.93 \\
\hline $7-12$ months ago & 156 & 14.8 \\
\hline 13-24 months ago & 52 & 4.93 \\
\hline Over 24 months ago & 83 & 7.87 \\
\hline Don't know/Don't remember & 204 & 19.35 \\
\hline \multicolumn{3}{|l|}{ Monthly Family Income } \\
\hline Up to I minimum wage & 103 & 9.3 \\
\hline Over I up to 2 minimum wages & 289 & 26.08 \\
\hline Over 2 up to 3 minimum wages & 269 & 24.28 \\
\hline Over 3 up to 5 minimum wages & 267 & 24.1 \\
\hline Over 5 up to 7 minimum wages & 97 & 8.75 \\
\hline Over 7 up to 10 minimum wages & 62 & 5.6 \\
\hline Higher than 10 minimum wages & 21 & 1.9 \\
\hline \multicolumn{3}{|l|}{ Community Periodontal Index (CPI) } \\
\hline No bleeding & 476 & 42.12 \\
\hline Bleeding on probing & 392 & 34.69 \\
\hline Dental calculus & 243 & 21.5 \\
\hline Periodontal pocket 4-5 mm & 18 & 1.59 \\
\hline Periodontal pocket $6 \mathrm{~mm}$ or more & I & 0.09 \\
\hline \multicolumn{3}{|c|}{ Oral Impacts on Daily Performances (OIDP) } \\
\hline Yes & 679 & 60.09 \\
\hline No & 451 & 39.91 \\
\hline
\end{tabular}


Table 3 shows the multilevel model for the response variable CPI From Model 1 the intra class correlation coefficient could be calculated $r=0.0037 /(0.0037+0.6755)=0.0054$. That is, the variation between the suburbs represents approximately $0.5 \%$ of the total variation. When the individual variables were included in Model 2, there was a reduction of approximately $10 \%$ in the 2 Res Log Likelihood. When the significant variable of suburb was included in Model 3, the reduction in comparison with the previous model was $0.04 \%$, confirming that the variation in CPI due to the variables related to the individu- als is more important than those related to the suburbs. Considering the level of significance of $5 \%$, by Model 2 it may be affirmed that the volunteers who declared that they had never had any toothache in their lives presented a lower CPI index $(\mathrm{p}=0.0008)$ and lower OIDP $(\mathrm{p}<0.0001)$. In addition to these variables relative to the individuals, in Model 3 one observes that the CPI was slightly reduced, but significantly (coefficient $=-0.0239, \mathrm{p}=0.0010$ ) with an increase in the percentage of domestic sewage in the volunteers' place of residence. The other variables had no significant influence on the CPI $(p>0.05)$.

Tabel 3 Multilevel model for community periodontal index (CPI)

\begin{tabular}{|c|c|c|c|c|c|c|c|c|c|}
\hline Variable & Model I & & & Model 2 & & & Model 3 & & \\
\hline & Estimate & SE & $\mathrm{p}$-value & Estimate & SE & $\mathrm{p}$-value & Estimate & SE & $\mathrm{p}$-value \\
\hline Intercept & 0.8311 & 0.0283 & $<0.0001$ & 0.08018 & 0.1097 & $<0.000$ I & 3.1326 & $0.7 \mid 48$ & $<0.0001$ \\
\hline \multicolumn{10}{|l|}{ Individual level } \\
\hline Toothache $(\mathrm{Ref}=\mathrm{No})$ & & & & 0.2074 & 0.0612 & 0.0007 & 0.2049 & 0.0609 & 0.0008 \\
\hline Socio-dental Impact (OIDP) & & & & 0.0075 & 0.0017 & $<0.0001$ & 0.0042 & 0.0075 & $<0.0001$ \\
\hline Suburb level \% of domestic sewage & & & & & & & -0.0239 & 0.0072 & 0.001 \\
\hline \multicolumn{10}{|l|}{ Variances } \\
\hline Between suburbs & 0.0037 & 0.0283 & & 0.0057 & 0.006 & & 0.0004 & 0.0035 & \\
\hline Between individuals & 0.6755 & 0.0287 & & 0.6429 & 0.0286 & & 0.6418 & 0.0285 & \\
\hline 2 Res Log Likelihood & 2773.21 & & & 2491.42 & & & 2490.28 & & \\
\hline
\end{tabular}

\section{Discussion}

This study obtained two important results, which must be better contextualized in this section. Periodontal disease was associated with individual variables (toothache during the course of life and sociodental indicator- OIDP) and a contextual variable (\% of domestic sewage in the suburb). Over the last few decades, the World Health Organization (WHO) has made an effort to emphasize the importance of oral health conditions as an important and in dissociable part of general health and the quality of life of people. ${ }^{55}$ Therefore, it has become necessary to understand and identify the determinant and modifying factors of the epidemiological situation found, which may influence the occurrence of periodontal disease. The development of a disease is related to the individual's behavior and his/her perception with regard to health habits. ${ }^{56}$ Self-perception of health has been associated with the oral health and quality of life indicators. ${ }^{57,58}$ Self-evaluation of oral health has also been directly and indirectly related to the factors of material inequalities, being stronger than the behavioral and psychosocial factors. ${ }^{21,22} \mathrm{~A}$ study about the theory of self-determination (SDT) of the oral health process has pointed out that the perception of these competencies was significantly positive and related to oral health and quality of life. ${ }^{59,60}$ The evaluation of health by means of subjective indicators is an important component for measuring oral health status and must be taken into consideration when preparing the approaches to diminishing inequities in health..$^{21,61}$ Moreover, it makes it possible to hear from individuals which of the areas of their lives are being affected, and thus evaluate the impact of oral health on daily activities. ${ }^{62}$ The results of this study showed evidence that the adolescents with greatest impact on their daily activities presented the worst periodontal conditions. ${ }^{63,64}$ The impact of periodontal disease on an individual is generally characterized by clinical parameters, such as probing, pocket depth, and bone attachment level. However, periodontal disease is an infectious-inflammatory process that causes destruction of the periodontium, and produces a vast variety of clinical signs and symptoms that may have a considerable impact on day-to- day or quality of life. ${ }^{37,63}$ In countries with recognized low prevalence of oral diseases, the psychological domain, represented by difficulty with smiling, appeared as one having the greatest impact on the performance of daily activities..$^{37,65}$ Another variable that influenced the CPI was "toothache". Adolescents with the highest CPI values related having had a larger number of toothache episodes during their lives. According to Santiago et al.${ }^{66} \&$ Bastos et al. ${ }^{67}$ a lower percentage of adolescents with toothache was found in a Brazilian suburb with higher social capital. In spite of the body of evidence that the inequalities in health are related to the social context, the large majority of studies about toothache contain information collected only at individual level, such as age, educational level, income, type of residence, participation in government aid programs, self-perception of oral health, access, among others.

As far as we know, there is no other epidemiologic study about the relationship of periodontal disease with toothache, adopting a multilevel approach. Toothache continues to be one of the main problems that lead to people seeking treatment, because it is of sufficiently great magnitude to have a negative impact on the daily life of the individual and community ${ }^{68}$ The relationship between toothache and periodontal disease is very intimate, however, the majority of epidemiological studies have associated the pain in a tooth with the pain of oral lesions (severe periodontal pocket or pulp lesion) or temporomandibular disorders. This may occur, because toothache itself is rarely defined in the literature and pain may be result of an odontogenic or non-odontogenic phenomenon. ${ }^{69}$ Although it was not our intention to infer that an episode of toothache, the identification of patients with past history of toothache allows one to identify patients at risk for various oral disease, and specifically, periodontal disease. Therefore, this helps in the sense of preventing this problem that is related to systemic diseases, such as diabetes ${ }^{70,71}$ and cardiopathies,${ }^{72}$ which may eventually lead to the patient's death. It seems that the findings of our study provide new insights into the influence of toothache and socio-dental impact on periodontal status. Future studies should be conducted on this issue, 
specially within the national context. Greater importance has been attributed to the association between social structure and oral health, and this has been incorporated into economic, social and behavioral aspects for understanding the diseases of the mouth. ${ }^{66}$ Therefore, it is necessary to identify those who are most vulnerable, as they are the ones that must be protected until such time that they come out of this situation, nevertheless respecting their cultural and moral differences and establishing communication between the health's of this population. ${ }^{73}$ This is particularly important when a deprived group is selected, and it reveals more specific information about how the variables of individual and contextual risks are modeled in a population previously defined as vulnerable. This study points out that the relationship between periodontal disease and domestic sewage in the suburb was statistically significant. The CPI diminished slightly, but significantly, with the increase in the percentage of domestic sewage in the volunteers' place of residence.

Another study has related basic sanitation to oral health, pointing out the role of sanitation and the supply of fluoridated water, specifically with regard to toothache.${ }^{66}$ However, as far as periodontal disease is concerned, there are no reports in the literature with the inclusion of this contextual variable in the analyses, although there is a tendency to perceive that in regions that present better sanitary conditions, there are better conditions of health. ${ }^{74}$ In reality, as the majority of the suburbs in the city of Piracicaba present $100 \%$ sewage treatment and water supply, small variations in a few suburbs of the city signify the full state of vulnerability, forming areas of social risk. These suburbs would present a low level of schooling, employment and education, in addition to normally being suburbs of occupation (established by unauthorized occupation) with a low percentage of basic services of life and health provided by the municipality. Adolescents who live in similar unfavorable social and economic situations may present different perceptions of periodontal disease. Possible explanations for this fact may be related to elements such as social capital, training and social support, which in turn translate into empowerment of individuals for coping with, and perception of adverse situations. ${ }^{65,75}$ Furthermore, it is possible that social capital presents positive interference, since it has been found that suburbs that generate high levels of social capital produce fewer risk behaviors, better mental health, more health promotion behaviors and better general perceptions of health. ${ }^{76}$ There has been a growth in social capital as a result of recognizing that behaviors related to health are molded and coerced by a variety of social and community contexts, and that the manners in which an individual relates to social and community networks has important effects on his/ her health and wellbeing. ${ }^{77,78}$ Possibly, the negative effects of stress can be greater for residents in disadvantaged neighborhoods with the least social support and fewest network resources, ${ }^{17,79}$ resulting worst level of health status. Given the complex inequalities there are in the adolescent's health, both nationally and internationally, when social capital acts as a factor of protection, it may help to reduce the damage. Therefore, measuring and evaluating the relative importance of a series of social indicators that represent the different domains of social capital in health, may be related to the behaviors of youngsters. ${ }^{80}$

Thus, to us, it appears to be important to encourage discussion about the determinants of oral health from a population health perspective based on conceptual multidimensional and multilevel models. The models supply a framework for research, policy-making, and for more effective resource allocation to improve oral health. ${ }^{81}$

In this sense, the present study meets the premises of such con- ceptual models, as biologic, social, environmental, health behavior variables and dental care outcomes are used, thereby influencing the oral health outcomes at individual, family, and community levels. One of the differentials of this study was the use of a multilevel model in the analysis of factors related to periodontal conditions in adolescents. Multilevel models are appropriate for analyzing hierarchical data, considering the influence of the community context on individual health behaviors, ${ }^{18,82-85}$ seeing that it is essential to analyze the data of health, disease and their determinant factors in order to consider the intricate process occurring between the individual and the environment, and considering the various interactions between the different levels studied. ${ }^{86}$ In addition we used a recent technique (PROC GLINMIX), which presents better estimates and gives substantive meanings to grouping data in comparison with the traditional regression analysis, allowing one to analyze contextual factors separately. ${ }^{17}$ The modeling of oral health data is rather complex, since these data generally do not present normal distribution. With the development of generalized linear models (an extension of linear models for data not normally distributed) this type of problem has been considerably reduced. Whereas mixed generalized linear models incorporate the random effects into the predictor are very useful when there is over dispersion of data. The application of mixed generalized linear models has been satisfactorily used in multilevel analysis. ${ }^{17,87}$ This study may possibly be one of the first to use this technique for studying the relations of individual and contextual variables with regard to periodontal disease, especially in adolescents. However, most of the variance in CPI occurred at the individual level with low impact of the contextual variables on the statistical model, similar to other studies. ${ }^{88,89}$ The evidence of an association between periodontal health individual and socioeconomic status level is equivocal, ${ }^{90}$ and it has been argued that periodontitis has a predominantly biological rather than a social etiology. ${ }^{89,91}$

Lastly, our study has some limitations. This was a cross-sectional study and sought inferences with regard to causal factors, without however, establishing a temporal relationship. The contextual data were obtained from government sources, which are subject to problems of under- or over-notification, processing errors, not updating indicators, and others. Furthermore, the contextual variables could have been complemented with the data with reference to social capital, social cohesion, social support, and social network, and could have reduced the unexplained community-level variance. ${ }^{79,92}$ Self perception questionnaire may have been influenced by social acceptance and social desirability. ${ }^{92,93}$ Moreover, the obtainment of data about income is very sensitive, and the respondents may not have provided accurate information. ${ }^{93}$ It was concluded that Individual and contextual variables were related to the periodontal disease in underprivileged Brazilian adolescents.

\section{Acknowledgements}

The authors wish to acknowledge the financial support from FAPESP (grants \#2011/03657-5 and \#2011/01768-4). We also give special thanks to the principals of the schools, teachers and all the adolescents who contributed to the accomplishment of the survey.

\section{Conflict of interest}

Author declares that there is no conflict of interest.

\section{References}

1. Van Dyke TE, Van Winkelhoff AJ. Infection and inflammatory mechanisms. J Clin Periodontol. 2013;40(Suppl 14):S1-S7. 
2. Brasil. Ministery of Health. SB Brasil 2010: National Oral Health Survey: principal results. 2012;106.

3. Jin LJ, Armitage GC, Klinge B, et al. Global oral health inequalities: task group-periodontal disease. Adv Dent Res. 2011;23(2):221-6.

4. Broadbent JM, Thomson WM, Boyens JV, et al. Dental plaque and oral health during the first 32 years of life. J Am Dental Assoc. 2011;142(4):415-26.

5. Levin L, Margvelashvili V, Bilder L, et al. Periodontal status among adolescents in Georgia: A pathfinder study. Peer J. 2013;1:e137.

6. Smith BT, Smith PM, Harper S, et al. Reducing social inequalities in health: the role of simulation modelling in chronic disease epidemiology to evaluate the impact of population health interventions. Journal of epidemiology and community health. 2013.

7. Sabbah W, Tsakos G, Sheiham A, et al. The role of health-related behaviors in the socioeconomic disparities in oral health. Soc Sci Med. 2009;68(2):298-303.

8. Polk DE, Weyant RJ, Manz MC. Socio-economic factors in adolescents oral health: are they mediated by oral hygiene behaviors or preventive interventions? Community Dent Oral Epidemiol. 2010;38(1):1-9.

9. Mashoto KO, Astrom NA, Skeie MS, et al. Socio-demographic disparity in oral health among the poor: a cross sectional study of early adolescents in Kilwa district, Tanzania. BMC Oral Health. 2010;20:10-7.

10. Borrell LN, Papapanou PN. Analytical epidemiology of periodontitis. $J$ Clin Periodontol. 2005;32 Suppl 6:132-58.

11. Peres MA, Antunes JLF, Boing AF, et al. Skin colour is associated with periodontal disease in Brazilian adults: a population-based oral health survey. J clin periodontol. 2007;34(3):196-201.

12. Bastos JL, Boing AF, Peres KG, et al. Periodontal outcomes and social, racial and gender inequalities in Brazil: a systematic review of the literature between 1999 and 2008. Cad Saude Publica. 2011;27(2):S14153.

13. Celeste RK, Nadanovsky P, Ponce de Leon A, et al. The individual and contextual pathways between oral health and income inequality in Brazilian adolescents and adults. Soc Sci Med. 2009;69(10):1468-1475.

14. Moreira RDS, Nico LS, Barrozo LV, et al. Tooth loss in Brazilian middleaged adults: multilevel effects. Acta Odontolo Scand. 2010;68(5):269277.

15. Celeste RK, Fritzell J, Nadanovsky P. The relationship between levels of income inequality and dental caries and periodontal diseases.Cad Saúde Pública. 2011;27(6):1111-1120.

16. Sheiham A, Nicolau B. Evaluation of social and psychological factors in periodontal disease. Periodontol 2000. 2005;39(1):118-131.

17. Nkansah Amankra S, Luchok KJ, Hussey JR, et al. Effects of Maternal Stress on Low Birth Weight and Preterm Birth Outcomes Across Neighborhoods of South Carolina, 2000-2003. Matern Child Health J. 2010;14(2):215-226.

18. Vettore MV, Marques RAA, Peres MA. Social inequalities and periodontal disease: multilevel approach in SBBrasil 2010 survey. Rev Saúde Pública. 2013;47 Suppl 3:29-39.

19. Thiengo MA, Oliveira DC, Rodrigues BMRD. Adolescents, Aids and protection practices: a structural approach of the social representations. Revista de Enfermagem UERJ. 2002;10(2):81-4.

20. Herrera D, Matesanz P, Bascones Martínez A, et al. Local and systemic antimicrobial therapy in periodontics. J Evid Based Dent Pract. 2012;12 Suppl 3:50-60.
21. Richter M, Moor I, Van Lenthe FJ. Explaining socioeconomic differences in adolescent self-rated health: the contribution of material, psychosocial and behavioural factors. $J$ Epidemiol Community Health. 2012;66(8):691-697.

22. Reyes L, Herrera D, Kozarov E, et al. Periodontal bacterial invasion and infection: contribution to atherosclerotic pathology. J Clin Periodontol. 2013;40 Suppl 14:S30-S50.

23. Alm A, Wendt LK, Koch G, et al. Caries in adolescence - influence from early childhood. Community Dent Oral Epidemiol. 2012;40:125-133.

24. Haggerty RJ, Sherrod LR, Gamezy N. Stress, risk and resilience in children and adolescents: process, mechanisms and interventions. New York: Cambridge University Press; 2000

25. Grünspun H. Conceitos sobre resiliência. Revista Bioética. 2003;10(1).

26. Sapienza G, Pedromônico MRM. Risk, protection and resilience in the development of children and adolescents. Psicologia em estudo. 2005;10(2):209-216

27. Heitz Mayfield LJ, Lang NP. Comparative biology of chronic and aggressive periodontitis vs. peri-implantitis. Periodontol 2000 2010;53:167-181.

28. Shum I, Leung PC, Kwok A, et al. Periodontal conditions in elderly men with and without osteoporosis or osteopenia. $J$ periodontol. 2010;81(10):1396-1402.

29. Mattheus DJ. Vulnerability related to oral health in early childhood: a concept analysis. $J$ Adv Nurs. 2010;66(9):2116-2125.

30. Nicolau B, Marcenes W, Hardy R, et al. A life-course approach to assess the relationship between social and psychological circumstances and gingival status in adolescents. J Clin Periodontol. 2003;30(12):10381045.

31. Das Munshi J, Clark C, Dewey ME, et al. Does childhood adversity account for poorer mental and physical health in second-generation Irish people living in Britain? Birth cohort study from Britain (NCDS). BMJ open. 2013;3(3):e001335.

32. Adulyanon S, Vourapukjaru J, Sheiham A. Oral impacts affect daily performance in a low dental disease Thai population. Community Dent Oral Epidemiol. 1996;24(6):385-389.

33. Abanto J, Carvalho TS, Mendes FM, et al. Impact of oral diseases and disorders on oral health? Related quality of life of preschool children. Community Dent Oral Epidemiol. 2011;39(2):105-114.

34. Sischo L, Broder HL. Oral Health-related Quality of Life What, Why, How, and Future Implications. J Dent Res. 2011;90(11):1264-1270.

35. Antunes JL, Tan H, Peres KG, et al. Impact of shortened dental arches on oral health-related quality of life. J Oral Rehabil. 2016;43(3):190-197.

36. Souza JG, Costa Oliveira BE, Martins AM. Contextual and individual determinants of oral health-related quality of life in older Brazilians. Qual Life Res. 2017;26(5):1295-1302.

37. Bulgareli JV, Faria ET, Cortellazzi KL, et al. Fatores que influenciam o impacto da saúde bucal nas atividades diárias de adolescentes, adultos e idosos. Rev Saude Publica. 2018;52:44.

38. Gomes AS, Abegg C. The impact of oral health on daily performance of municipal waste disposal workers in Porto Alegre, Rio Grande do Sul State, Brazil. Cad Saúde Pública. 2007;23(7):1707-1714.

39. Sheiham A. A determinação de necessidades de tratamento odontológico: uma abordagem social. In: Pinto VG. Saúde bucal coletiva. São Paulo, editors Santos. 2000;223:50-91.

40. Silva AN, Silva CMFP, Vettore MV. Are resilience and maternal sense 
of coherence associated with gingival status in adolescents from lowincome families? Int J Paediatric Dent. 2014;24(6):450-9.

41. Peres MA, Peres KG, Cascaes AM, et al. Validity of partial protocols to assess the prevalence of periodontal outcomes and associated sociodemographic and behavior factors in adolescents and young adults. J Periodontol. 2012;83(3):369-78.

42. Aquino R, Oliveira NF, Barreto ML. Impact of the family health program on infant mortality in Brazilian municipalities. Am J Public Health 2009;99(1):87-93.

43. IBGE. Brazilian Institute of Geography and Statistic. 2014

44. World Health Organization. Oral Health Surveys. Basic Methods. 4th ed. Geneva: World Health Organization, 1997.

45. Landis JR, Koch GG. The measurement of observer agreement for categorical data. Biometrics. 1977;33(1):159-74.

46. Meneghim MC, Kozlowski FC, Pereira AC, et al. A socioeconomic classification and the discussion related to prevalence of dental caries and dental fluorosis. Ciên Saúde Colet. 2007;12(2):523-529.

47. Goes PSA. The prevalence and impact of dental pain in Brazilian schoolchildren and their families. London; Dep Epidemiol Public Health; 2001.

48. Skevington SM, Lotfy M, O Connell KA. The World Health Organization's WHOQOL-BREF quality of life assessment: psychometric properties and results of the international field trial. A report from the WHOQOL group. Qual life Res. 2004;13:299-310.

49. BRASIL. Ministery of Health. Secretary of Health Atention. Department of Primary Health Care. Manual of Primary Atention Information System. 2000.

50. Rasella D, Aquino R, Santos CA, et al. Effect of a conditional cash transfer programme on childhood mortality: a nationwide analysis of Brazilian municipalities. Lancet. 2013;382:57-64.

51. BRASIL. Ministery of Health. Secretary of Health Atention. Department of Primary Health Care. Manual guidance on the Family in Health. 3 ed. 2010 .

52. IPPLAP. Piracicaba Institute of Planning and Research. 2011.

53. IBGE. Brazilian Institute of Geography and Statistic. 2013.

54. SAS Institute Inc 2001: SAS/STAT Guide for personal computers version 9.2. Cary: North-Carolina/USA.

55. Petersen PE. The World Oral Health Report 2003: continuous improvement of oral health in the 21st century-the approach of the WHO Global Oral Health Programme. Community Dent Oral Epidemiol. 2003;31(1):3-23.

56. Hattne K, Folke S, Twetman S. Attitudes to oral health among adolescents with high caries risk. Acta Odontol Scand. 2007;65(4):206-213.

57. Somkotra T. Socioeconomic inequality in self-reported oral health status: the experience of Thailand after implementation of the universal coverage policy. Community Dent Health. 2011;28:136-42.

58. Paula JS, Leite IC, Almeida AB, et al. The influence of oral health conditions. socioeconomic status and home environment factors on schoolchildren's self-perception of quality of life. Health Qual Life Outcomes. 2012;10:6.

59. Locker D. Issues in measuring change in self-perceived oral health status. Community Dent Oral Epidemiol. 1998;26(1):41-47.

60. Halvari AE, Halvari H, Bjørnebekk G, et al. Oral health and dental well? being: testing a self-determination theory model. J Appl Soc Psychol.
$2013 ; 43(2): 275-292$.

61. Newton JT, Bower EJ. The social determinants of oral health: new approaches to conceptualizing and researching complex causal network. Community Dent Oral Epidemiol. 2005;33(1):25-34.

62. Marshman Z, Robinson PG. Child and Adolescent Oral Health-Related Quality of Life. Semin Orthod. 2007;13:88-95.

63. Needleman I, McGrath C, Floyd P, et al. Impact of oral health on the life quality of periodontal patients. J Clin Periodontol. 2004;31:454-457.

64. $\mathrm{Ng} \mathrm{SK}$, Leung WK. Oral health-related quality of life and periodontal status. Community Dentd Oral Epidemiol. 2006;34(2):114-122.

65. Bianco A, Fortunato L, Nobile CG, et al. Prevalence and determinants of oral impacts on daily performance: results from a survey among school children in Italy. Eur J Public Health. 2010;20(5):595-600.

66. Bastos JLD, Gigante DP, Peres KG, et al. Social determinants of odontalgia in epidemiological studies: theoretical review and proposed conceptual model. Ciênc. Saúde Coletiva. 2007;12(6):1611-1621.

67. Santiago BM, Valença AMG, Vettore MV. Social capital and dental pain in Brazilian northeast: a multilevel cross-sectional study. BMC Oral Health. 2013;13:2.

68. Goes PS, Watt RG, Hardy R, Sheiham A. Impacts of dental pain on daily activities of adolescents aged 14-15 years and their families. Acta Odontologica. 2008;66(1):7-12.

69. Sutherland S, Matthews DC. Emergency Management of Acute Apical Periodontitis in the Permanent Dentition: A Systematic Review of the Literature. J Can Dent Assoc. 2003;69(3):160.

70. Norris SL, Nichols PJ, Caspersen CJ, et al. The effectiveness of disease and case management for people with diabetes: a systematic review. $\mathrm{Am}$ J Prev Med. 2002;22(4):15-38

71. Shimazaki Y, Saito T, Yonemoto K, et al. Relationship of metabolic syndrome to periodontal disease in Japanese women: the Hisayama Study. J Dent Res. 2007;86(3):271-275.

72. Tonetti MS, Dyke TE. Periodontitis and atherosclerotic cardiovascular disease: consensus report of the Joint EFP/AAP Workshop on Periodontitis and Systemic Diseases. J Clin Periodontol. 2013;84 Suppl 4:S24-S29.

73. Costa SDM, Abreu M, Vasconcelos M, et al. Inequalities in the distribution of dental caries in Brazil: a bioethical approach. Ciên Saúde Colet. 2013;18(2):461-470.

74. Baldani MH, Narvai PC, Antunes JLF. Dental caries and socioeconomic conditions in the State of Paraná, Brazil, 1996. Cad Saude Publica. $2002 ; 18(3): 755-63$.

75. Wamala S, Merlo J, Boström G. Inequity in access to dental care services explains current socioeconomic disparities in oral health: the Swedish National Surveys of Public Health 2004-2005. J Epidemiol Community Health. 2006;60(12):1027-1033.

76. Richter M, Erhart M, Vereecken CA, et al. The role of behavioura factors in explaining socio-economic differences in adolescent health: a multilevel study in 33 countries. Soc Sci Med. 2009;69:396-403.

77. Bambra C, Gibson M, Sowden A, et al. Tackling the wider social determinants of health and health inequalities: evidence from systematic reviews. J Epidemiol Community Health. 2010;64(4):284-291.

78. Lorenc T, Petticrew M, Welch V, et al. What types of interventions generate inequalities? Evidence from systematic reviews. J Epidemiol Community Health. 2013;67(2):190-193.

79. O Campo P. Invited commentary: advancing theoryand methods for 
multilevel models of residential neighborhoods and health. $A m J$ Epidemiol. 2003;157:9-13.

80. Morgan A, Haglund BJ. Social capital does matter for adolescent health: evidence from the English HBSC study. Health Promo Int. 2009;24(4):363-372.

81. Fisher Owens SA, Gansky SA, Platt LJ, et al. Influences on children's oral health: a conceptual model. Pediatrics. 2007;120(3):e510-e520.

82. Leyland AH, Goldstein H. Multilevel modelling of health statistics New York. Wiley; 2001:1-12.

83. Hox JJ. Multilevel analysis, techniques and applications. Mahwah: Lawrence Erlbaum Associates; 2002:1-36.

84. Pattussi MP, Olinto MTA, Hardy R, et al. Clinical, social and psychological factors associated with self-rated oral health in Brazilian adolescents. Community Dent Oral Epidemiol. 2007;35:377-86.

85. Aida J, Hanibuchi T, Nakade M, et al. The different effects of vertical social capital and horizontal social capital on dental status: a multilevel analysis. Soc Sci Med. 2009;69(4):512-518.

86. Moreira TP, Nations MK, Alves MDSCF. Inequality and damaged teeth: oral sequelae from living in poverty in the Dendê community. Cad Saude Publica. 2007;23(6):1383-1392.
87. Huang FL, Invernizz MA. Birthday effects and preschool attendance. Early Childhood Research Quarterly. 2013;28(1):11-23.

88. Antunes JLF, Peres MA, Jahn GMJ, et al. The use of dental care facilities and oral health: a multilevel approach of schoolchildren in the Brazilian context. Oral Health Prev Dent. 2006;4(4):287-94.

89. Bower E, Gulliford M, Steele J, et al. Area deprivation and oral health in Scottish adults: a multilevel study. Community Dent Oral Epidemiol. 2007;35(2):118-129.

90. Klinge B, Norlund A. A socio-economic perspective on periodontal diseases - a systematic review. J Clin Periodontol. 2005;32(6):314-25.

91. Unell L, Söderfeldt B, Halling A, et al. Explanatory models for indicators of periodontal disease in an adult population. $J$ Clin Periodontol. 2000;27(1):22-9.

92. Aida J, Kondo K, Kondo N, et al. Income inequality, social capital and self-rated health and dental status in older Japanese. Soc Sci Med. 2011;73(10):1561-1568

93. Perera I, Ekanayake L. Influence of oral health-related behaviours on income inequalities in oral health among adolescents. Community Dent Oral Epidemiol. 2011;39:345-351. 